\title{
Performance Evaluation and Slip Regulation Control of an Asymmetrical Parameter Type Two-Phase Induction Motor Drive Using a Three-Leg Voltage Source Inverter
}

\author{
Wekin Piyarat Non-member (King Mongkut's Institute of Technology Ladkrabang, wkhot@hotmail.con) \\ Vijit Kinnares Non-member (King Mongkut’s Institute of Technology Ladkrabang, kkwijit@kmitl.ac.th)
}

Keywords: slip regulation control, asymmetrical parameter type two-phase induction motor drive, three-leg voltage source inverter, sinusoidal PWM

SPIMs (Single Phase Induction Motors) are widely used for fixed speed in low power residential and industrial applications such as HVAC (Heating, Ventilating and Air Conditioning) blowers and compressors. SPIMs are normally supplied with a single-phase ac source of constant frequency and voltage. They are commonly used in small ratings where a 3-phase supply is not usually available. However, SPIMs have encountered several problems such as low efficiency, low power factor, torque pulsations. Power electronic equipment has been introduced for the starting and speed control of SPIMs replacing conventional methods. Moreover, this equipment is able to cope with the improvement of the motor performance. More importantly, energy saving has been made possible with variable speed drives. A SPIM can operate as a two phase motor in order to improve performance. An asymmetrical parameter type two phase induction motor is possibly adapted from an existing SPCIM (Single Phase Split Capacitor Induction Motor) by removing a capacitor out from the auxiliary winding and separating main and auxiliary windings. This modified two-phase induction motor could be considered as an alternative choice for household appliance in which a three-phase induction motor and three-phase mains supply are not available and the performance of the existing SPCIM needs to be improved for variable speed drives. Many research efforts have been made in improving the drive performance not only by a control method but also by a PWM strategy. Various converter topologies were also evaluated and designed. Although advanced high performance control techniques such as direct torque control, speed sensorless control and flux vector control of the two-phase motor have been proposed, most of publications are concerned with the simulation.

This paper focuses on the performance evaluation in terms of electromagnetic torque, current, speed etc. and the simple speed control method as shown in Fig. 1. The drive system uses a dSPACE DS1104 DSP controller board with a TMS320F240 slave digital signal processor for the control process and the PWM generation.

The simulation and experimental results have shown the capability of the proposed system in four quadrant operation as shown in Fig. 2. Fig. 3 exhibits the dynamic response of the electromagnetic torque and currents during load disturbance operation. Theoretical and experimental results are in very good agreement. With these performance results, the proposed drive system has the potential in practically variable speed drive applications.

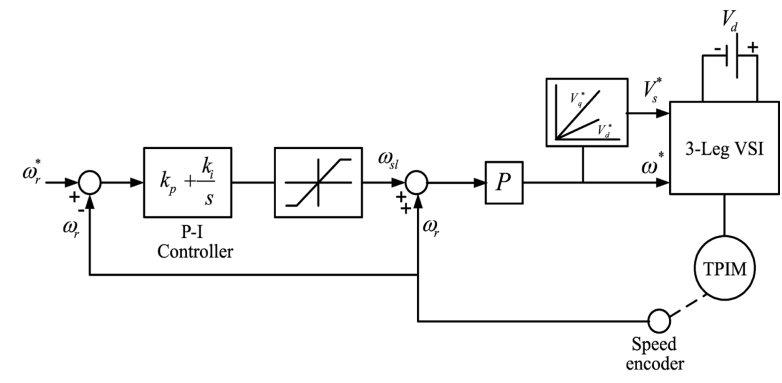

Fig. 1. Proposed system drive using slip frequency control with constant V/F

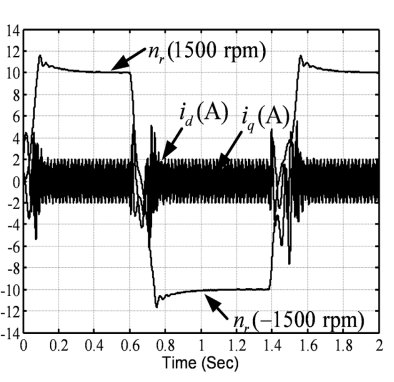

(a) Simulation

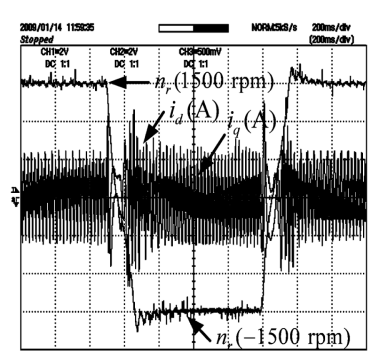

(b) Experimental
Fig. 2. Dynamic response of currents and speed during speed reversal operation (four quadrant operation)

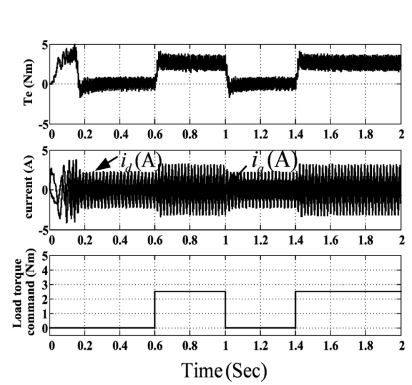

(a) Simulation

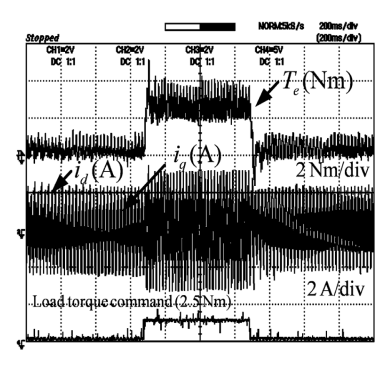

(b) Experimental
Fig. 3. Dynamic response of electromagnetic torque and currents during load disturbance operation 


\title{
Performance Evaluation and Slip Regulation Control of an Asymmetrical Parameter Type Two-Phase Induction Motor Drive Using a Three-Leg Voltage Source Inverter
}

\author{
Wekin Piyarat $^{*}$ Non-member \\ Vijit Kinnares* ${ }^{*}$ Non-member
}

\begin{abstract}
This paper presents a performance evaluation and a simple speed control method of an asymmetrical parameter type two-phase induction motor drive using a three-leg VSI (Voltage Source Inverter). The two-phase induction motor is adapted from an existing single-phase induction motor resulting in impedance unbalance between main and auxiliary windings. The unbalanced two-phase inverter outputs with orthogonal displacement based on a SPWM (Sinusoidal Pulse Width Modulation) method are controlled with appropriate amplitudes for improving the motor performance. Dynamic simulation of the proposed drive system is given. A simple speed controller based on a slip regulation method is designed. The overall system is implemented on a DSP (Digital Signal Processor) board. The validity of the proposed system is verified by simulation and experimental results.
\end{abstract}

Keywords: Slip regulation control, Asymmetrical parameter type two-phase induction motor drive, Three-leg voltage source inverter, sinusoidal PWM

\section{Introduction}

SPIMs (Single Phase Induction Motors) are widely used for fixed speed in low power residential and industrial applications such as HVAC (Heating, Ventilating and Air Conditioning) blowers and compressors. SPIMs are normally supplied with a single-phase ac source of constant frequency and voltage. They are commonly used in small ratings where a 3phase supply is not usually available. However, SPIMs have encountered several problems such as low efficiency, low power factor, torque pulsations ${ }^{(1)(2)}$. Power electronic equipment has been introduced for the starting and speed control of SPIMs replacing conventional methods. Moreover, this equipment is able to cope with the improvement of the motor performance. More importantly, energy saving has been made possible with variable speed drives.

A SPIM can operate as a two phase motor in order to improve performance. The study of this operation can be found in Refs. (1)-(3) (6)-(8) (10) (12) (18). An asymmetrical parameter type two phase induction motor is possibly adapted from an existing SPCIM (Single Phase Split Capacitor Induction Motor) by removing a capacitor out from the auxiliary winding and separating main and auxiliary windings. This modified two-phase induction motor could be considered as an alternative choice for household appliance in which a three-phase induction motor and three-phase mains supply are not available and the performance of the existing SPCIM needs to be improved for variable speed drives. Many research efforts have been made in improving the drive performance not only by a control method but also by a PWM strategy $^{(1)-(14)}$. Various converter topologies were also evaluated

\footnotetext{
* Department of Electrical Engineering, Faculty of Engineering, King

Mongkut's Institute of Technology Ladkrabang

3, Moo2, Chalong Krung Rd., Bangkok 10250, Thailand
}

and designed ${ }^{(2)(5)}$.

As shown in Fig. 1, a three-leg VSI providing two phase outputs is increasingly attractive for two-phase drive applications due to good dc voltage utilization, reduced total harmonic distortion of currents and availability of threeleg modules ${ }^{(3)(6)}$ and ${ }^{(12)}$. When comparing with the two-leg VSI for a two-phase induction motor, the three-leg VSI offers zero space vectors resulting in a reduction in the motor current ripple and more or less $20 \%$ higher output phase voltages ${ }^{(6)}$ and ${ }^{(17)}$. Also, the problem of unbalanced voltages across two DC-link capacitors is absent for the threeleg VSI. The comparative performance evaluation between two-leg and four-leg VSI drives can be found in Ref. (1). A two-leg VSI provides the lower motor performance than a four-leg VSI because of the quality of PWM scheme as well as dc link voltage utilization. Some publications have reported the three-leg VSI drives with their own modulation strategies $^{(3)-(6)}$ and ${ }^{(12)}$. The conclusions of comparable performance between three-leg and four-leg topologies were reported in Ref. (6). However, the four-leg VSI has a major drawback in a switching device count resulting in increased cost, complicated structure, and reduced reliability. Additionally, the three-leg topology is now available in a commercially compact IPM (Intelligent Power Module). When optimizing between cost and performance of the drive system, the three-leg VSI is more attractive. Unbalanced twophase voltage supplies with variable frequency have proved better performance of an asymmetrical parameter type two phase induction motor ${ }^{(3)(10)}$ and ${ }^{(12)-(14)}$. However, an accurate dynamic modeling and a profound performance evaluation are required.

Although advanced high performance control techniques such as direct torque control, speed sensorless control and flux vector control of the two-phase motor have been 


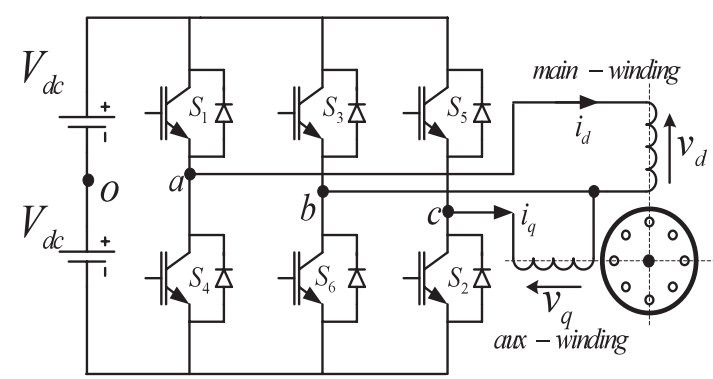

Fig. 1. Three-leg PWM voltage source inverter supplying a two-phase induction motor

proposed $^{(22)-(26)}$, most of publications are concerned with the simulation. A simple scalar control is hardly reported ${ }^{(16)}$ for practical works. However, the simple scalar control offers some advantages in terms of a simplicity and an acceptable response in which some applications require.

This paper focuses on the performance evaluation in terms of electromagnetic torque, current, speed etc. and the simple speed control method. The organizing of this paper is as follows. Firstly, principle of a PWM scheme is explained. Then, dynamic model of the two-phase asymmetrical induction motor is given. The simple speed control method based on the slip regulation is proposed. Finally, the simulation and experimental results are discussed and compared in order to verify the correctness of the proposed system.

\section{SPWM Strategy}

2.1 Balanced Two-Phase Outputs According to the main power circuit of Fig. 1, the relation between three-phase and two-phase voltages can be illustrated in a phasor diagram form as shown in Fig. 2. Using the three-phases as references, the two-phase outputs $\left(\tilde{V}_{d}, \tilde{V}_{q}\right)$, obtained from the voltage difference of a pair of three phases using phase $b$ as a common phase, are quadrature with balanced voltage values.

Instantaneous equations of phase leg fundamental voltages of the main power circuit can be expressed as follows.

$$
\begin{aligned}
& v_{a o, 1}=m V_{d c} \sin (\omega t) \cdots \\
& v_{b o, 1}=m V_{d c} \sin \left(\omega t-\frac{\pi}{2}\right) \\
& v_{c o, 1}=m V_{d c} \sin (\omega t-\pi)
\end{aligned}
$$

As a consequence, instantaneous two-phase fundamental voltages of the outputs are as follows:

$$
\begin{array}{r}
v_{d 1}=v_{a b, 1}=v_{a o, 1}-v_{b o, 1}=\overbrace{m \sqrt{2} V_{d c}}^{\text {Amplitude }} \cos \left(\omega t-\frac{\pi}{4}\right) \\
\ldots \ldots \ldots \ldots \ldots \ldots \ldots \ldots \ldots \ldots \ldots \\
v_{q 1}=v_{c b, 1}=v_{c o, 1}-v_{b o, 1}= \\
\overbrace{m \sqrt{2} V_{d c}}^{\text {Amplitude }} \cos \left(\omega t+\frac{\pi}{4}\right)
\end{array}
$$

where

$m=$ the modulation index (ratio of the peak of a sinusoidal reference to the peak of a triangular carrier) and $0 \leq m \leq 1$

$V_{d c}=$ the midpoint dc link voltage.

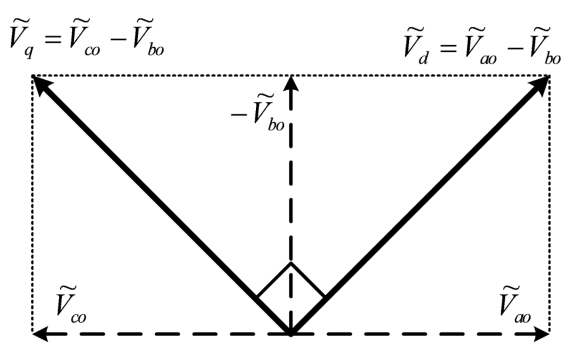

Fig. 2. Three-phase and Two-phase phasor diagram

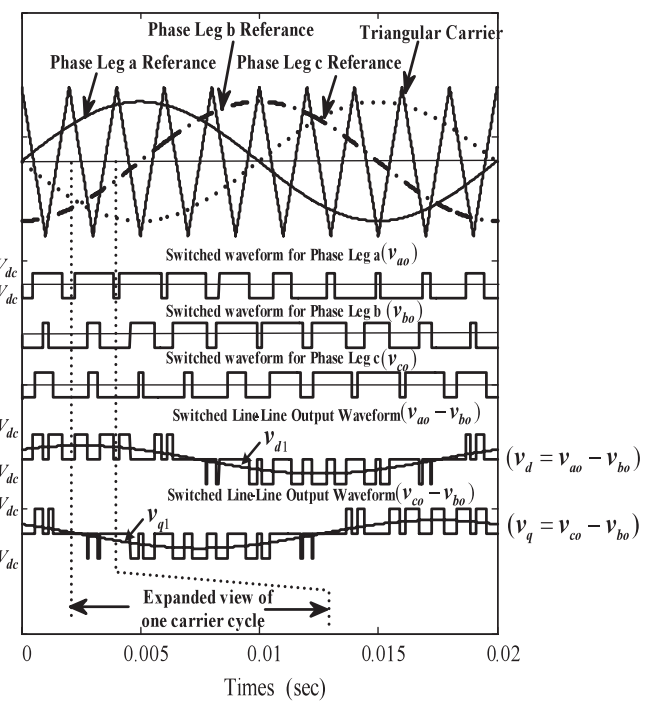

(a)

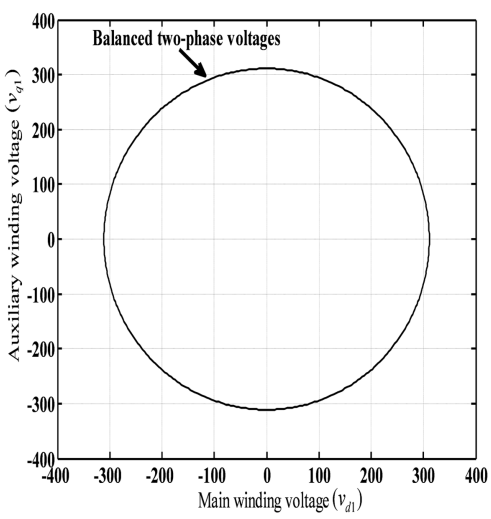

(b)

Fig. 3. (a) PWM pattern of balanced two-phase outputs using the three-leg VSI (b) Corresponding trajectory of two-phase fundamental outputs with $V_{d c}$ of $310 \mathrm{~V}$

The principle of generating PWM pattern and trajectory of balanced two-phase fundamental outputs of the SPWM method can be illustrated as shown in Fig. 3. Two-phase PWM output voltages $v_{d}$ and $v_{q}$ are obtained from the voltage difference between two-legs among three legs defining phase leg b as a common phase leg. Using (4) and (5), the plotted trajectory of two-phase fundamental outputs for $V_{d c}$ of $310 \mathrm{~V}$ is perfectly circular. It means that each phase has equal amplitude and orthogonal displacement. The detailed switching process can be illustrated in the expanded carrier period as shown in Fig. 4. Two-phase PWM output voltages are obtained from the switched line-to-line voltages. 


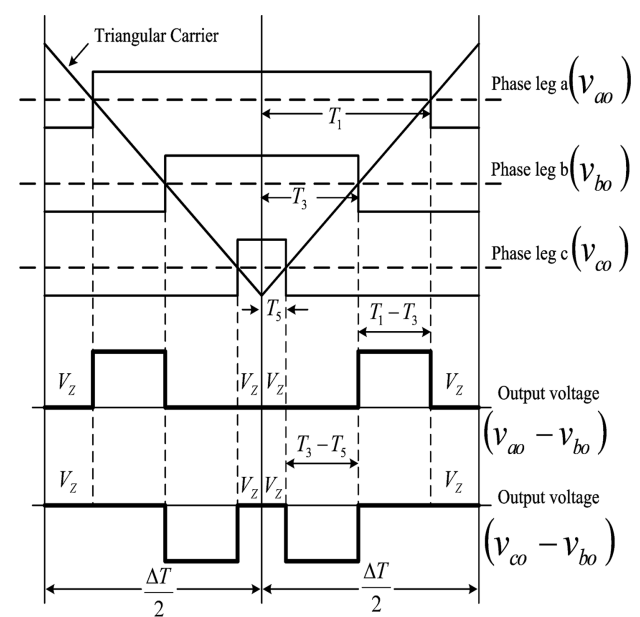

Fig. 4. Expanded view of a carrier period of Two-phase output voltages

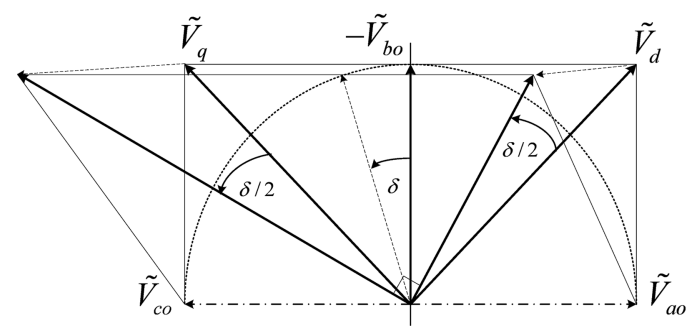

Fig. 5. Phasor diagram of unbalanced two-phase outputs

2.2 Unbalanced Two-Phase Outputs In order to implement the unbalanced output SPWM, the phasor diagram of the balanced output SPWM is used as a reference for modifying. The phasor can be created as shown in Fig. 5. Phase $\mathrm{b}$ is shifted by a phase angle $\delta$ resulting in a change in values of direct axis voltag $\left(V_{d}\right)$ and quadrture axis voltage $\left(V_{q}\right)$. As a consequece the value of $V_{q}$ is greater than that of $V_{d}$ whilst the phase difference is still 90 degrees. Only the instataneous equation of $v_{b o, 1}$ is changed into

$$
v_{b o, 1}=m V_{d c} \sin \left(\omega t-\frac{\pi}{2}+\delta\right)
$$

Therefore, the instantaneous fundamental of the two-phase outputs are as follows.

$$
\begin{aligned}
v_{d 1} & =\overbrace{a b, 1}=v_{a o, 1}-v_{b o, 1} \\
& =\overbrace{m 2 V_{d c} \sin \left(\frac{\pi}{4}-\frac{\delta}{2}\right)}^{\text {Amplitude }} \cos \left(\omega t-\frac{\pi}{4}+\frac{\delta}{2}\right) \ldots \ldots \\
v_{q 1} & =\overbrace{v_{c b, 1}=v_{c o, 1}-v_{b o, 1}}^{\text {Amplitude }} \\
& =\overbrace{m 2 V_{d c} \cos \left(\frac{\pi}{4}-\frac{\delta}{2}\right)} \cos \left(\omega t+\frac{\pi}{4}+\frac{\delta}{2}\right) \ldots \ldots
\end{aligned}
$$

Similar to the switching process for the balanced twophase outputs, the principle of generating PWM pattern and trajectory of unbalanced two-phase fundamental outputs can be illustrated as shown in Fig. 6. Using (7) and (8), the plotted trajectory of unbalanced two-phase fundamental outputs for $V_{d c}$ of $310 \mathrm{~V}$ is perfectly elliptical having a vertically major axis. It means that each phase has different amplitude,

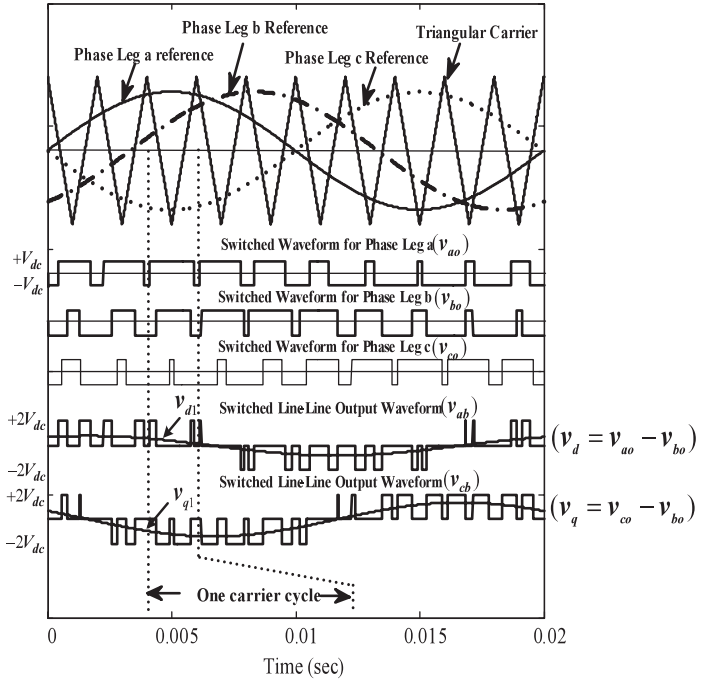

(a)

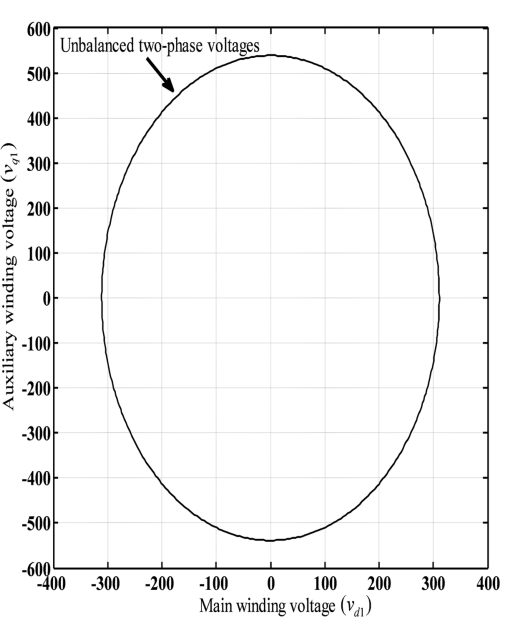

(b)

Fig. 6. (a) PWM pattern of unbalanced two-phase outputs using the three-leg VSI (b) Corresponding trajectory of two-phase fundamental outputs with $V_{d c}$ of $310 \mathrm{~V}$

the phase difference is still 90 degrees and the fundamental amplitude of $v_{q}$ is greater than that of $v_{d}$.

Using (4), (5), (7), and (8), the relationship between the fundamental outputs and the modulation index can be plotted as shown in Fig. 7. The two-phase fundamental outputs are proportional to the modulation index for both balanced and unbalanced cases. For the unbalanced case, the auxiliary winding voltage is greater than the main winding voltage with the relationship of $V_{q}=\alpha V_{d}$ where $\alpha$ is a constant. Note that the modulation is proportional to the inverter frequency (F) in order to maintain constant air-gap flux level (i.e. constant $\mathrm{V} / \mathrm{F}$ ). The loci of two-phase outputs for balanced and unbalanced cases under constant $\mathrm{V} / \mathrm{F}$ operation are shown in Fig. 8 at different inverter frequencies. Obviously for the balanced case, the loci shapes are perfectly circular. The higher inverter frequency is, the larger size of the circle occurs. On the other hand, for the unbalanced two-phase outputs, the loci shapes are a perfectly elliptical having a vertically major axis. The higher inverter frequency is, the larger size of the elliptic is achieved. 


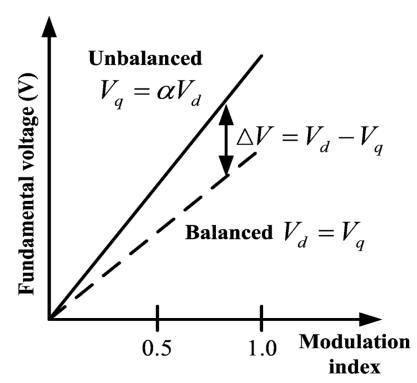

Fig. 7. Variation of two-phase voltages with the modulation index for balanced and unbalanced two-phase outputs

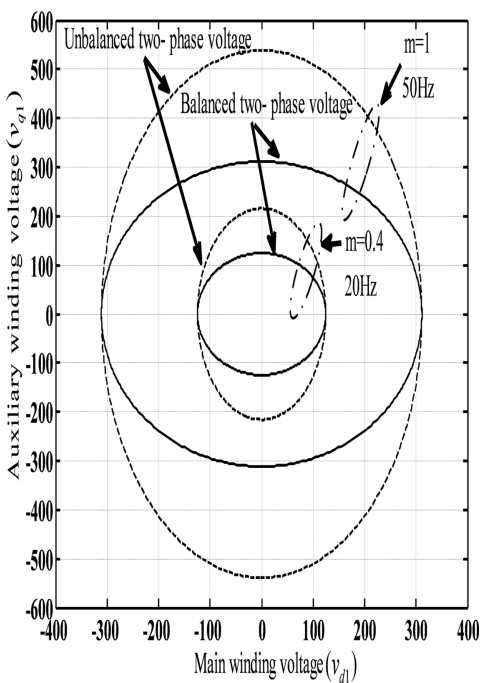

Fig. 8. Loci of output voltages under V/F control for balanced and unbalanced two-phase outputs

\section{Dynamic Model of Symmetrical Parameter type Two-Phase Induction Motor}

A mathematical model of unbalanced two-phase machines in the stationary frame neglecting core saturation and iron losses can be described as the following equations ${ }^{(6)}$.

$$
\begin{aligned}
& v_{s d}^{s}=R_{s d} i_{s d}^{s}+\frac{d \lambda_{s d}^{s}}{d t} \ldots \ldots \\
& v_{s q}^{s}=R_{s q} i_{s q}^{s}+\frac{d \lambda_{s q}^{s}}{d t} \ldots \ldots \\
& 0=R_{r} i_{s d}^{s}+\frac{d \lambda_{r d}^{s}}{d t}+\omega_{r} \lambda_{r q}^{s} \\
& 0=R_{r} i_{s q}^{s}+\frac{d \lambda_{r q}^{s}}{d t}-\omega_{r} \lambda_{r d}^{s} \\
& \lambda_{s d}^{s}=L_{s d} i_{s d}^{s}+M_{s r d} i_{r d}^{s} \ldots \\
& \lambda_{s q}^{s}=L_{s q} i_{s q}^{s}+M_{s r q} i_{r q}^{s} \ldots \\
& \lambda_{r d}^{s}=L_{r} i_{r d}^{s}+M_{s r d} i_{s d}^{s} \ldots \\
& \lambda_{r q}^{s}=L_{r} i_{r q}^{s}+M_{s r q} i_{s q}^{s} \ldots
\end{aligned}
$$

Where $v_{s d}^{s}, v_{s q}^{s}, i_{s d}^{s}, i_{s q}^{s}, i_{r d}^{s}, i_{r d}^{s}, \lambda_{s d}^{s}, \lambda_{s q}^{s}, \lambda_{r d}^{s}$ and $\lambda_{r q}^{s}$ are d-q axis voltages, currents and fluxes of stator and rotor in the stator reference frame. $R_{s d}, R_{s q}$ and $R_{r}$ denote the stator and rotor resistances. $L_{s d}, L_{s q}, L_{r}, M_{s r d}$ and $M_{s r q}$ denote the stator and the rotor self- and mutual inductances. $\omega_{r}$ is the rotor speed in $\mathrm{rad} / \mathrm{s}$.

The instantaneous electromagnetic torque produced by the machine is then given by

$$
T_{e}=P\left(i_{s q}^{s} i_{r d}^{s} M_{s r q}-i_{s d}^{s} i_{r q}^{s} M_{s r d}\right)
$$

The electromechanical equation of the machine is presented as:

$$
P\left(T_{e}-T_{L}\right)=J \frac{d \omega_{r}}{d t}+B \omega_{r}
$$

where $P, J$ and $B$ are the machine pole pairs, inertia and viscous friction coefficient, respectively.

Due to an asymmetrical feature, mutual inductance $M_{\text {srd }}$ is not equal to $M_{s r q}$. As a result, the electromagnetic torque ripple seriously occurs. This effect will be obviously demonstrated in the later section. In order to eliminate the ripple of the electromagnetic torque, an appropriate control of the stator currents is required ${ }^{(22)}$.

The mathematical expression of the electromagnetic torque can be rearranged in the terms of machine parameters and rotor fluxes through (9)-(16) as

$$
\begin{aligned}
T_{e}= & P\left(i_{s q}^{s}\left(\frac{\lambda_{r d}^{s}-M_{s r d} i_{s d}^{s}}{L_{r}}\right) M_{m s q}\right. \\
& \left.-i_{s d}^{s}\left(\frac{\lambda_{r q}^{s}-M_{s r q} i_{s q}^{s}}{L_{r}}\right) M_{m s d}\right) \\
= & \frac{P}{L_{r}}\left(i_{s q}^{s} \lambda_{r d}^{s} M_{s r q}-i_{s d}^{s} \lambda_{r q}^{s} M_{s r d}\right)
\end{aligned}
$$

where $i_{r d}^{s}=\frac{\lambda_{r d}^{s}-M_{s r d} i_{s d}^{s}}{L_{r}}$ and $i_{r q}^{s}=\frac{\lambda_{r q}^{s}-M_{s r q} i_{s q}^{s}}{L_{r}}$

$$
T_{e}=\frac{P}{L_{r}}\left(i_{s q}^{s} \lambda_{r d}^{s} M_{s r q}-i_{s d}^{s} \lambda_{r q}^{s} M_{s r d}\right)
$$

Then, the imposed stator currents can be given as

$$
\begin{aligned}
& i_{s d}^{s^{\prime}}=i_{s d}^{s} . \\
& i_{s q}^{s^{\prime}}=\alpha i_{s q}^{s}
\end{aligned}
$$

With $\alpha=M_{s r q} / M_{s r d}$ and substituting the variables $i_{s d}^{s}$ and $i_{s q}^{s}$ by $i_{s d}^{s^{\prime}}$ and $i_{s q}^{s^{\prime}}$, respectively into (19b), the torque can be rearranged as

$$
\begin{aligned}
T_{e} & =\frac{P}{L_{r}}\left(\frac{i_{s q}^{s^{\prime}}}{\alpha} \lambda_{r d}^{s} M_{s r q}-i_{s d}^{s^{\prime}} \lambda_{r q}^{s} M_{s r d}\right) \\
& =\frac{P}{L_{r}}\left(\frac{M_{s r d}}{M_{s r q}} i_{s q}^{s^{\prime}} \lambda_{r d}^{s} M_{s r q}-i_{s d}^{s^{\prime}} \lambda_{r q}^{s} M_{s r d}\right) \\
T_{e} & =\frac{P M_{s r d}}{L_{r}}\left(i_{s q}^{s^{s^{\prime}}} \lambda_{r d}^{s}-i_{s d}^{s^{\prime}} \lambda_{r q}^{s}\right) \ldots \ldots \ldots \ldots . . . . . . . .
\end{aligned}
$$

This expression is equivalent to that of the symmetric machine in which the oscillating term disappears in the steady state resulting in a circularly rotating flux vector. It means that the magnitude of $i_{s d}^{s^{\prime}}$ is equal to that of $i_{s q}^{s^{\prime}}$. According to (20) and (21), the relation between current magnitudes of both windings for an asymmetrical parameter type ${ }^{(12)}$ is

$$
I_{d}=\alpha I_{q}
$$


$I_{q}$ must lead $I_{d}$ by $90^{\circ}$. Then, based on the view of power balance, the relation of supplied voltages for both windings is approximately as

$$
V_{q}=\alpha V_{d}
$$

Note that $V_{q}$ is generally greater than $V_{d}$.

\section{Controller Design}

The speed controller is of the PI (Proportional-Integral) type. Fig. 9 shows the block diagram of the slip compensation control with constant V/F. The principle of operation of the control scheme is as follows. Firstly, the actual motor speed $\omega_{r}$ is compared with its speed command $\omega_{r}^{*}$ to produce the slip speed $\omega_{s l}$ conditioned by the PI regulator and a limiter to limit the excursion of the slip speed to maximum predetermined value. Secondly, the desired angular frequency $\omega^{*}$ of the inverter is then obtained by the sum of the feedback speed and the slip speed multiplied by the number of pole-pairs $(P)$. Finally, the stator voltages for both windings are obtained from the desired angular frequency which are proportional. The auxiliary winding voltage is related to the main winding voltage according to (24).

Fig. 10 shows the block diagram of a simple closed loop speed control. Assuming that at a rated motor flux level, the maximum electromagnetic torque can be produced at small slip frequency, the relationship between the electromagnetic torque and the slip speed of the two-phase motor with the voltage compensation can be treated as that of a three-phase induction motor ${ }^{(20)}$ on the basis of the balanced system. Then

$$
T_{e}=k_{t} \omega_{s l}
$$

where $k_{t}=T_{\text {rated }} / \omega_{\text {sl, rated }}$.

The Laplace domain of the above can be expressed as

$$
T_{e}(s)=k_{t} \omega_{s l}(s)
$$

By neglecting load disturbance, the Laplace domain of the rotor speed can be expressed as

$$
\omega_{r}(s)=\frac{T_{e}(s)}{J s}
$$

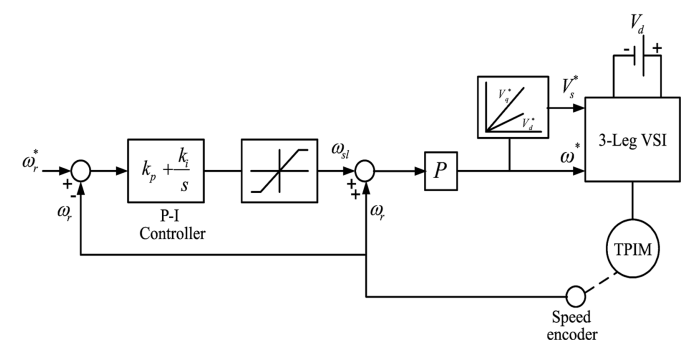

Fig. 9. Proposed system drive using slip frequency control with constant $\mathrm{V} / \mathrm{F}$

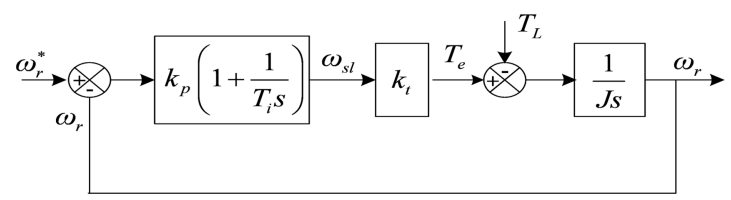

Fig. 10. Simplified closed loop control system representation
The transfer function between the rotor speed and the slip speed is

$$
\frac{\omega_{r}(s)}{\omega_{s l}(s)}=\frac{k_{t}}{J_{s}}
$$

The open loop transfer function of the speed loop in the block diagram of Fig. 10 is

$$
H(s)=k_{p}\left(1+\frac{1}{T_{i} s}\right) \cdot\left(\frac{k_{t}}{J S}\right)=\frac{k_{p} k_{t}\left(1+T_{i} s\right)}{\left(T_{i} s\right)(J s)} \cdots \cdots
$$

Considering the magnitude and phase components of (29) at the crossover frequency $\omega_{c}$ results in $|H(s)|=\left|H\left(j \omega_{c}\right)\right|=1$ and the phase margin $\varphi_{M}=180^{\circ}+\tan ^{-1}\left(\omega_{c} T_{i}\right)-90^{\circ}-90^{\circ}$ where

$$
\begin{aligned}
T_{i} & =\frac{\tan \varphi_{M}}{\omega_{c}} \ldots \ldots \ldots \ldots \ldots \ldots \ldots \ldots \ldots \ldots \ldots \ldots \ldots \ldots \ldots \\
k_{p} & =\frac{T_{i} J s^{2}}{k_{t}+k_{t} T_{i} s}=\frac{T_{i} J\left(\omega_{c}\right)^{2}}{k_{t} \sqrt{1+\left(T_{i} \omega_{c}\right)^{2}}} \\
T_{i} & =\frac{k_{p}}{k_{i}} \ldots \ldots \ldots \ldots \ldots \ldots \ldots
\end{aligned}
$$

Bode plot of the open loop of (29) is shown in Fig. 11. According to Bode plot, cut-off frequency $\omega_{c}$ is about $36.9 \mathrm{rad} / \mathrm{s}$. Therefore if the selected phase margin is $60^{\circ}$ in conjunction with $k_{t}=0.196$ obtained from the rated parameter values of (25), then $T_{i}=0.047 \mathrm{sec}$. As a consequence, using (31) and (32) results in $k_{p}=1.65$ and $k_{i}=35.1$, respectively. The stability of the system can be verified from Fig. 12. Clearly overall system poles are on the left hand side. According to the root locus plot, the damping factor $(\zeta)$ is about 0.6 . Overshoot is approximately $9.2 \%$ which is within acceptable value. The natural frequency $\left(\omega_{n}\right)$ is approximately $26.5 \mathrm{rad} / \mathrm{s}$.

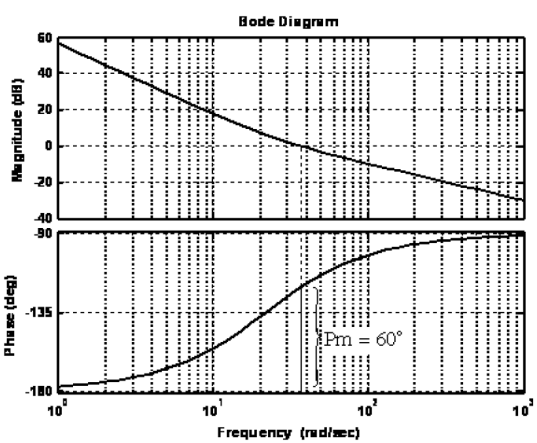

Fig. 11. Frequency response of the open loop

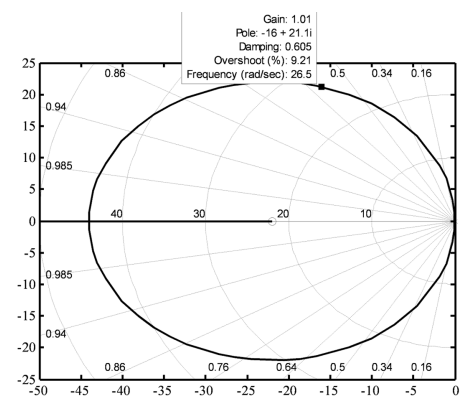

Fig. 12. Root locus of the closed loop control system 


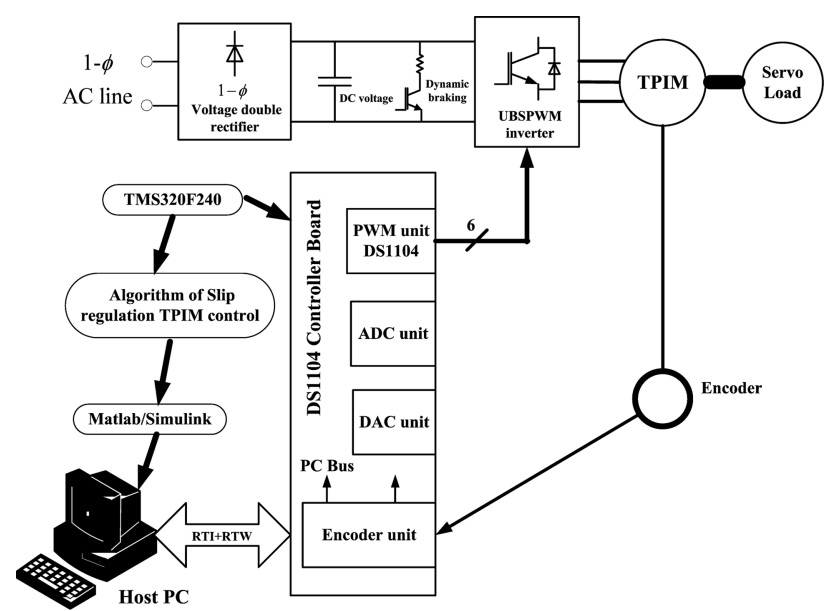

Fig. 13. The proposed drive system

\section{Simulation and Experimental Results}

The overall system for verifying the performance of the proposed control method is shown in Fig. 13. The drive uses a dSPACE DS1104 DSP controller board with a TMS320F240 slave digital signal processor for the control process and the PWM generation. In order to ensure that the inverter is able to provide the appropriate voltages for both windings of the motor under test, the dc bus voltage of the inverter input is obtained from a single-phase voltage double rectifier. The three-leg IGBT Intelligent power module inverter is used with fixed switching frequency of $5 \mathrm{kHz}$. The servo drive acts as a loading system providing accurate load torque. The $370 \mathrm{~W}$ asymmetrical two-phase induction motor is adapted from an existing SPCIM by removing a capacitor out from the auxiliary winding and separating main and auxiliary windings. The detail of motor parameters is given in Appendix A.

The Matlab/Simulink software is used to simulate the motor performance driven by the three-leg VSI at $50 \mathrm{~Hz}$ with open loop speed operation under start-up and load disturbance conditions for both balanced and unbalanced applied voltages. Fig. 14 shows various performances in terms of speed, currents, electromagnetic torque and stator flux for the dynamic response. Obviously, when comparing the performance during start-up, the speed response of the motor for unbalanced two-phase applied voltages is faster than for balanced two-phase applied voltages. This shows that the unbalanced voltage case provides better acceleration torque. For the load disturbance at $0.4 \mathrm{~s}$ and $2.5 \mathrm{Nm}$ applied torque, again, the unbalanced supplied voltages gives lower speed drop. This shows that the unbalanced voltage case gives better speed regulation than the balanced case. Clearly, the electromagnetic torque pulsation for the unbalanced case is lower than for the balanced case. In order to confirm this performance, the torque spectra are shown in Fig. 15. It is noticeable that the double supply frequency component (i.e. $100 \mathrm{~Hz}$ ) for the balanced case is significantly greater than for the unbalanced case whilst the average torque values for both cases are the same which are the values of the applied load torque. The important evidence to confirm the good performance in terms of electromagnetic torque is the loci of the
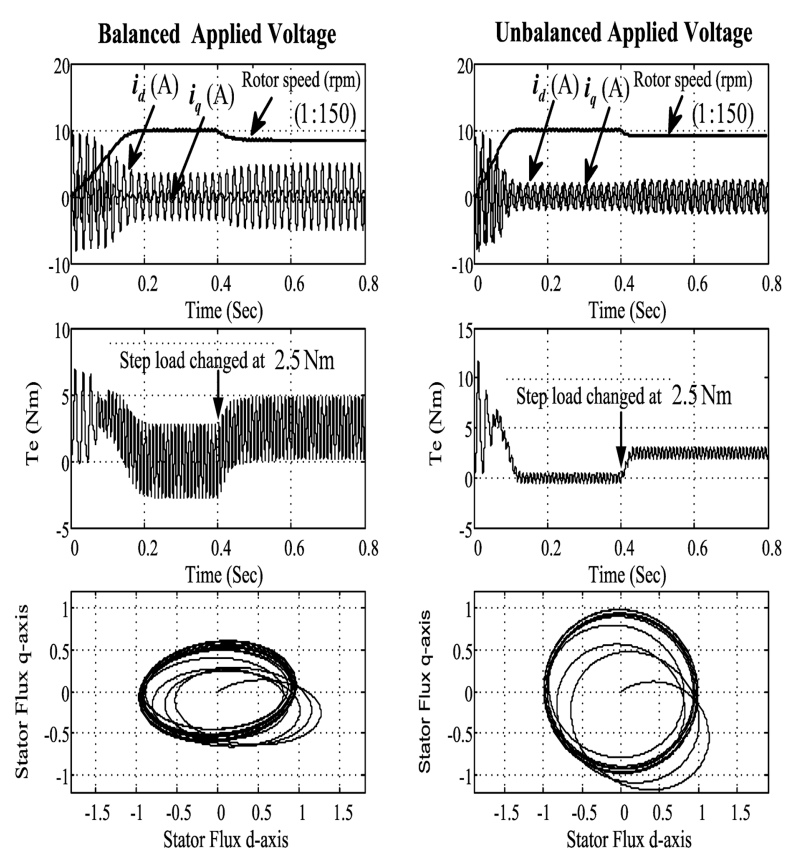

Fig. 14. Dynamic response during start-up and load disturbance operations

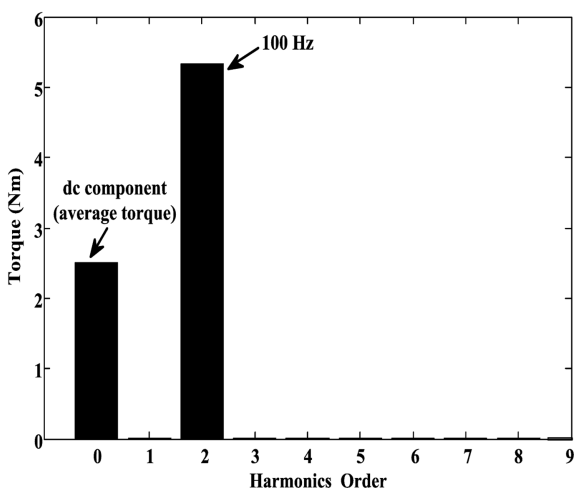

(a)

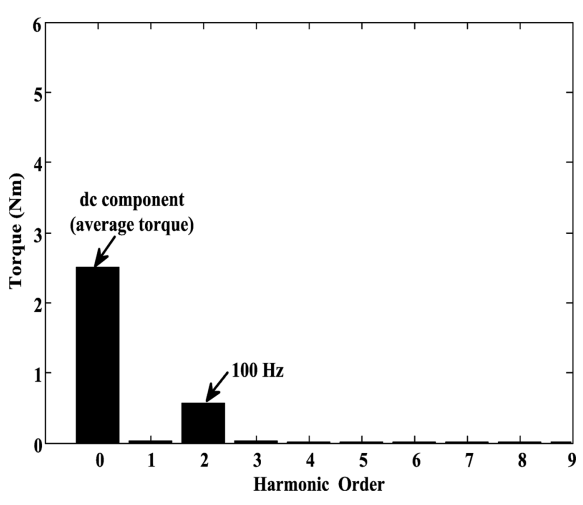

(b)

Fig. 15. Torque spectra (a) for balanced applied voltages (b) for unbalanced applied voltages

stator flux as shown in Fig. 14. Apparently, the loci of the stator flux for the unbalanced case is a nearly circular shape whilst the loci of the stator flux for the balanced case is an elliptical shape. This implies that the MMF (Magneto-Motive Force) for the unbalanced case is much better than for the balanced case leading to a reduction in torque pulsation.

Fig. 16 shows torque-speed characteristics at various 


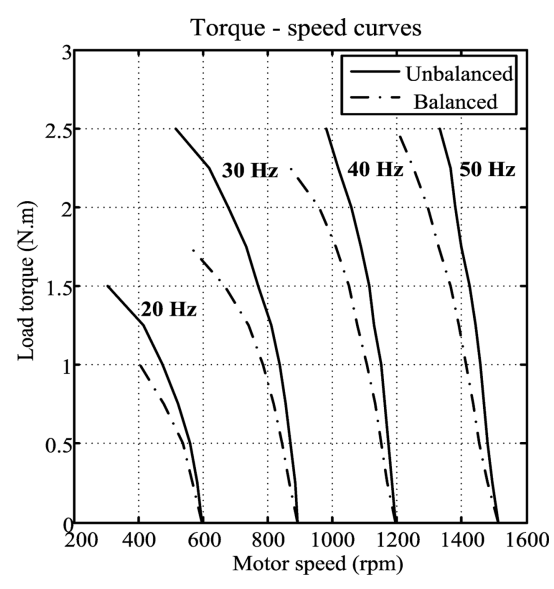

Fig. 16. Torque-speed capability of both balanced and unbalanced two-phase outputs
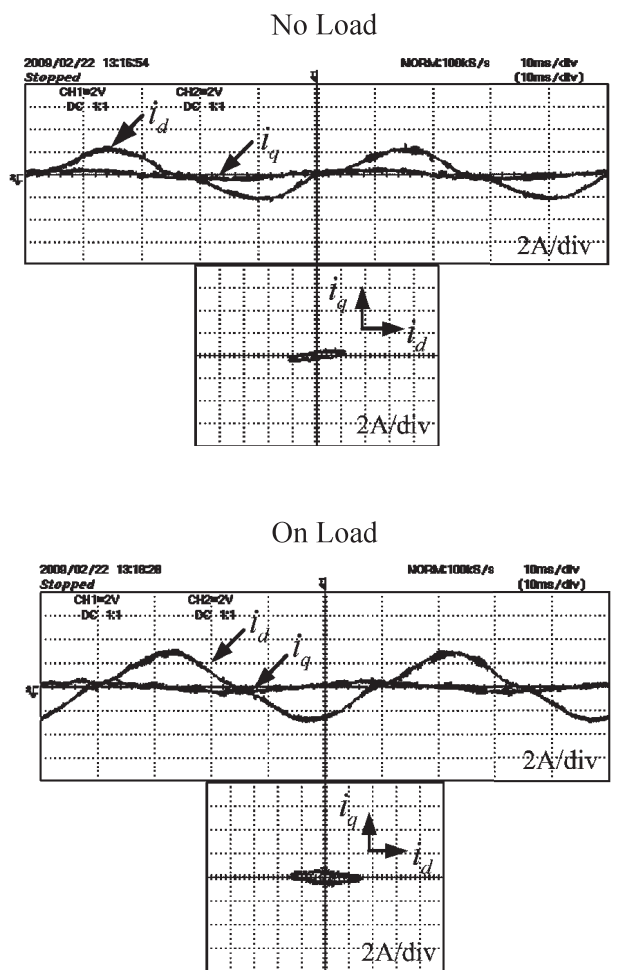

Fig. 17. Waveforms of motor currents and corresponding trajectories at inverter frequency of $20 \mathrm{~Hz}$ under no load and load torque of $2.5 \mathrm{Nm}$ for balanced two-phase outputs

inverter frequencies obtained from the experiment under open loop speed operation for balanced and unbalanced cases. Clearly, the improvement of the electromagnetic torque is achieved by the unbalanced two-phase outputs. At the same load torque, the speed regulation of the motor supplied with the unbalanced voltages is much better than that supplied with the balance voltages. However, for both cases, at lower inverter frequencies, the motor needs a voltage boost in order to maintain a rated flux level resulting in constant maximum torque operation.

Figs. 17 and 18 exhibit motor current waveforms and their corresponding trajectories under no load and on load operations at inverter frequencies of $20 \mathrm{~Hz}$ and $50 \mathrm{~Hz}$, respectively for the balanced supplied voltages. The magnitude of the
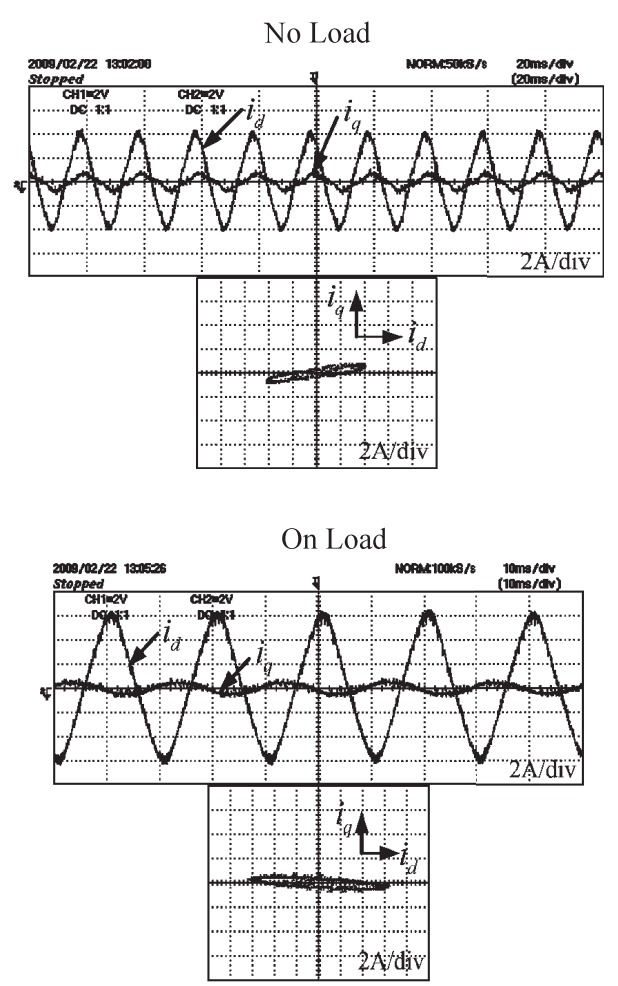

Fig. 18. Waveforms of motor currents and corresponding trajectories at inverter frequency of $50 \mathrm{~Hz}$ under no load and load torque of $2.5 \mathrm{Nm}$ for balanced two-phase outputs

auxiliary current $i_{q}$ is lower than the main winding current $i_{d}$. It is noticeable that when applying load torque at inverter frequency of $50 \mathrm{~Hz}$, the magnitude of $i_{d}$ increases whilst the magnitude of $i_{q}$ insignificantly changes. Obviously, the current trajectories are perfectly elliptical shapes. For on load operation the almost horizontally major axis of the elliptic is achieved whilst for no load operation, the elliptical axis is shifted away from the horizontal axis. Quite clearly, the load torque affects the size of the trajectory shape.

Figs. 19 and 20 illustrate motor current waveforms and their corresponding trajectories under no load and on load operations at inverter frequencies of $20 \mathrm{~Hz}$ and $50 \mathrm{~Hz}$, respectively for the unbalanced supplied voltages. The magnitude of the auxiliary current is less than that of the main winding current. The ratio of the magnitude of $i_{d}$ to that of $i_{q}$ is about 1.75 which is the same value of the ratio of the magnitude of the auxiliary winding voltage $\left(v_{q}\right)$ to that of the main winding voltage $\left(v_{d}\right)$ as mentioned before. The magnitude of $i_{d}$ decreases whilst that of $i_{q}$ increases compared to those for the balanced case resulting in getting bigger shapes of the elliptical trajectories. Apparently, the current trajectories become bigger elliptical shapes approaching to circular shapes when comparing to those for the balanced supplied voltages. These imply that the better electromagnetic torque can be obtained. The load torque also affects the size of the trajectory shape.

Fig. 21 shows the unbalanced fundamentals and harmonic spectra for both windings at inverter frequency of $20 \mathrm{~Hz}$. Note that the ratio of the auxiliary winding fundamental voltage to the main winding fundamental voltage (i.e. $\alpha$ ) is approximately 1.75 which is nearly equal to the value given in Appendix A. The harmonic spectra for both windings are 

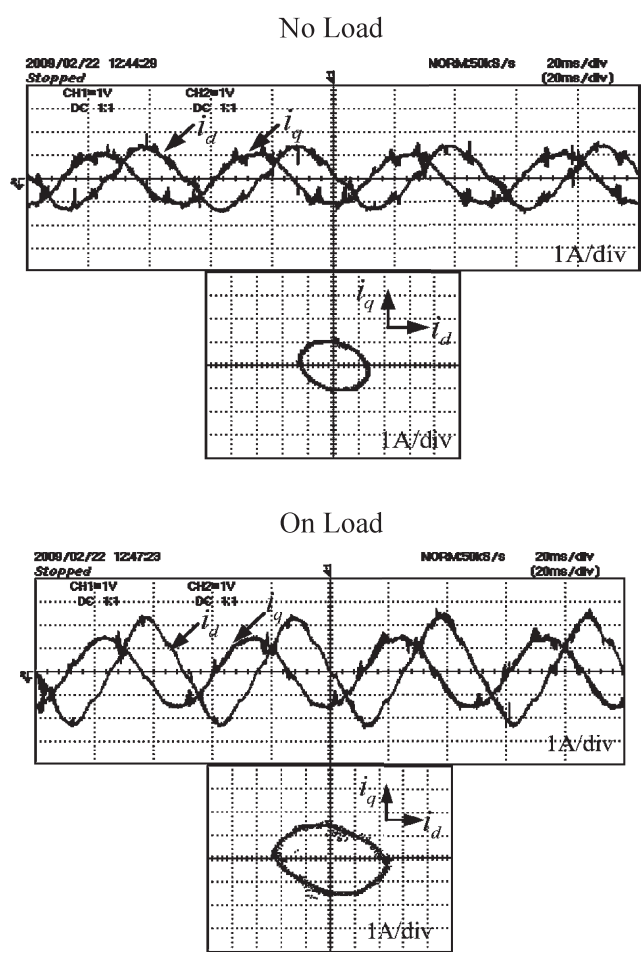

Fig. 19. Waveforms of motor currents and corresponding trajectories at inverter frequency of $20 \mathrm{~Hz}$ under no load and load torque of $2.5 \mathrm{Nm}$ for unbalanced two-phase outputs
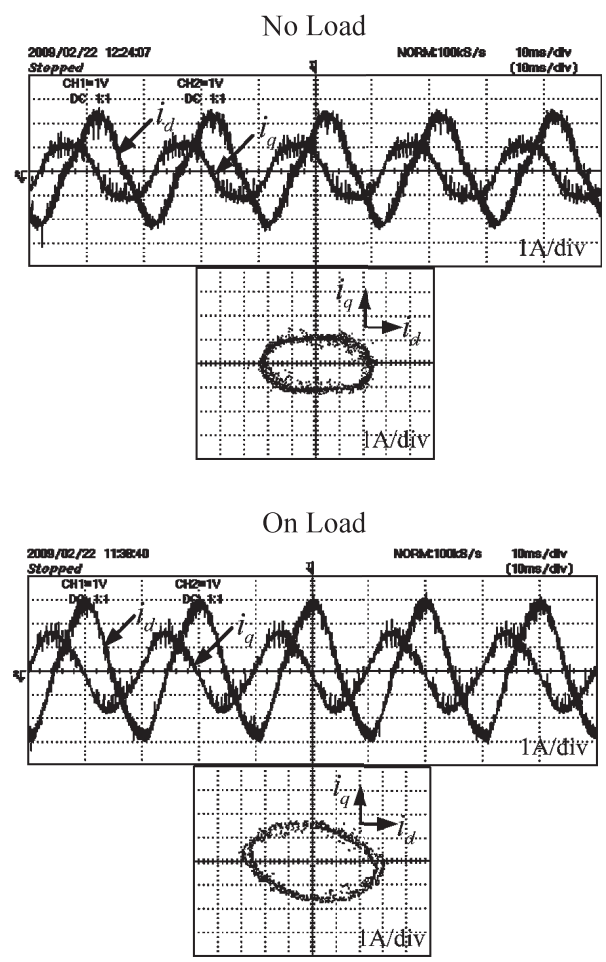

Fig. 20. Waveforms of motor currents and corresponding trajectories at inverter frequency of $50 \mathrm{~Hz}$ under no load and load torque of $2.5 \mathrm{Nm}$ for unbalanced two-phase outputs

similar. The harmonic sidebands are around multiples of switching frequency (i.e. $5,10,15,20 \mathrm{kHz}$, etc.). This confirms the correctness of the PWM generation.

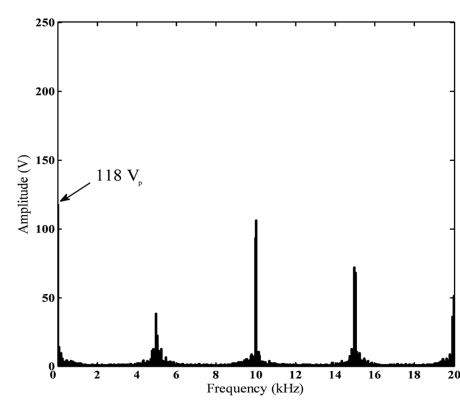

(a)

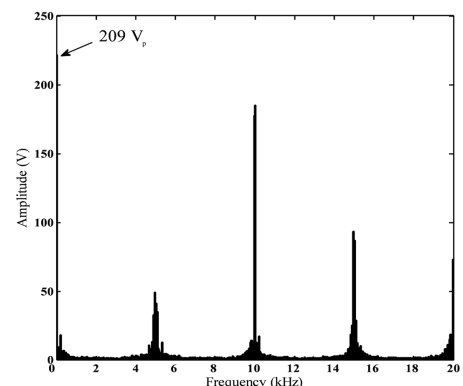

(b)

Fig. 21. Harmonic voltage spectra at inverter frequency of $20 \mathrm{~Hz}$ (a) for $v_{d}$ (b) $v_{q}$

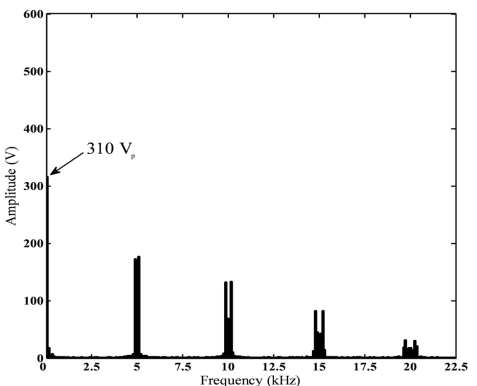

(a)

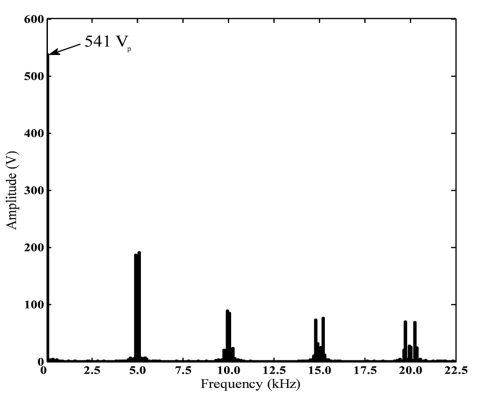

(b)

Fig. 22. Harmonic voltage spectra at inverter frequency of $50 \mathrm{~Hz}$ (a) for $v_{d}$ (b) $v_{q}$

Fig. 22 shows the unbalanced fundamentals and harmonic spectra for both windings at inverter frequency of $50 \mathrm{~Hz}$. Again, the ratio of both winding fundamental voltages (i.e. $\alpha$ ) is still approximately 1.75 . The harmonic spectra for both windings are similar. The amplitudes of the harmonic sidebands are lower than those for inverter frequency of $20 \mathrm{~Hz}$ except at the first harmonic sidebands. This characteristic is affected by the modulation index $\left(m_{a}\right)$ of the SPWM scheme. The harmonic sidebands are still around multiples of switching frequency (i.e. 5, 10, 15, $20 \mathrm{kHz}$, etc.). This again confirms the correctness of the asynchronous PWM operation. 


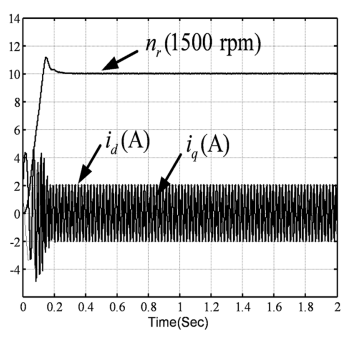

(a) Simulation

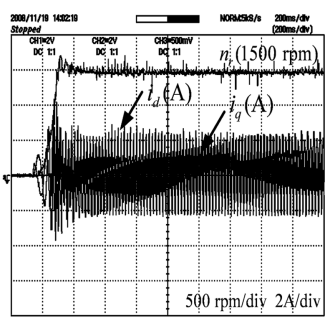

(b) Experimental
Fig. 23. Dynamic response of currents and speed during start-up operation

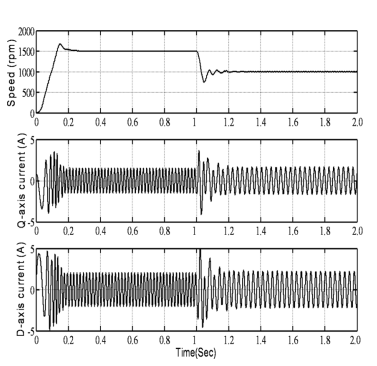

(a) Simulation

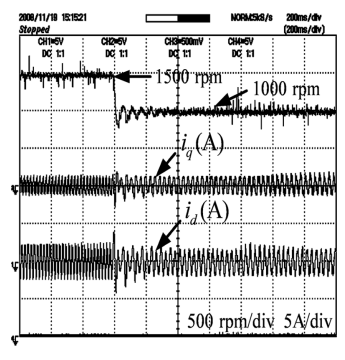

(b) Experimental
Fig. 24. Dynamic response of currents and speed during braking operation

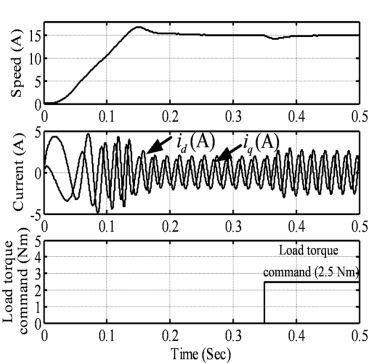

(a) Simulation

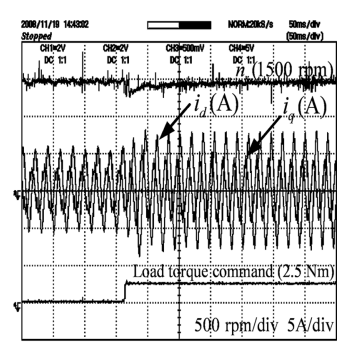

(b) Experimental
Fig. 25. Dynamic response of currents and speed during load disturbance operation

Figs. 23-26 illustrate comparison of the dynamic response between simulation and experiment with the closed loop speed control using the slip speed regulation with V/F control. During start-up operation with the speed command of $1500 \mathrm{rpm}$, simulation and experimental results are in very good agreement. The time response is reasonable in accordance with the controller design. During braking operation (a speed decrease) and load disturbance of $2.5 \mathrm{Nm}$ torque, simulation and experimental results are also in very good agreement. The motor speed is kept constant at $1500 \mathrm{rpm}$ and the time response is less than $0.1 \mathrm{~s}$ which is satisfactory and in accordance with the controller design. During speed reversal operation, the drive is able to operate effectively. It can be seen that the proposed drive system is capable of running in four quadrant operation. Again, the theoretical and experimental results are in very good agreement.

Figs. 27-28 exhibit the dynamic response of the electromagnetic torque and currents during start-up and load disturbance operations, the theoretical and experimental results are in very good agreement as well. With these performance results, the proposed drive system has the potential in practically variable speed drive applications.

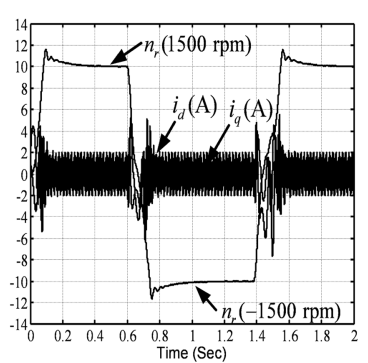

(a) Simulation

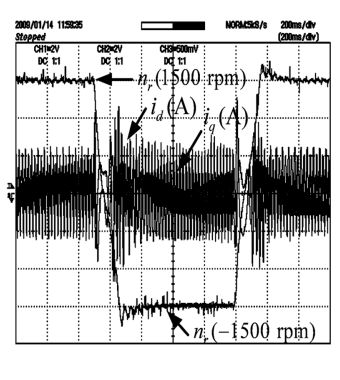

(b) Experimental
Fig. 26. Dynamic response of currents and speed during speed reversal operation (four quadrant operation)
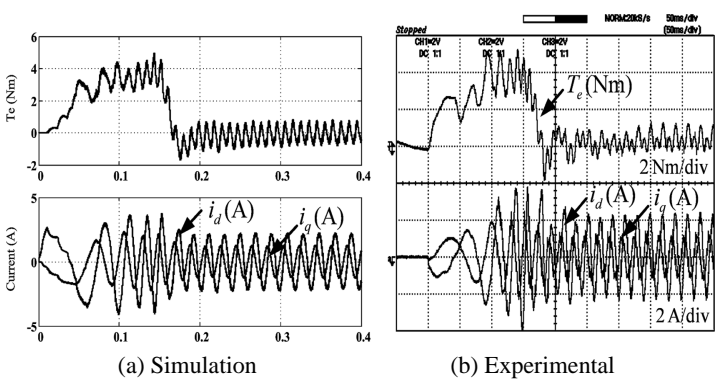

Fig. 27. Dynamic response of electromagnetic torque and currents during start-up operation

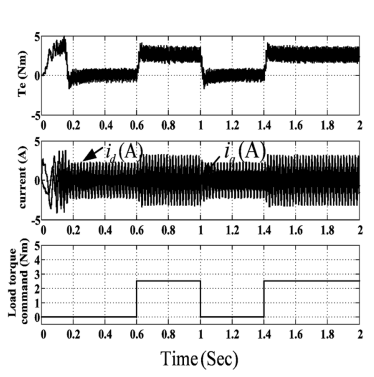

(a) Simulation

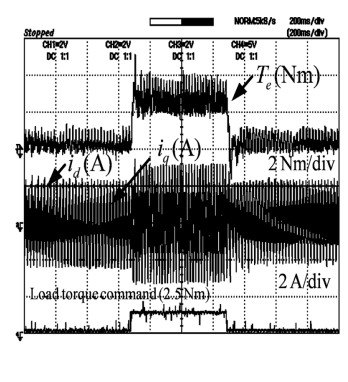

(b) Experimental
Fig. 28. Dynamic response of electromagnetic torque and currents during load disturbance operation

\section{Conclusions}

This paper has dealt with a performance evaluation and a simple speed control method of a three-leg VSI fed unbalanced two-phase induction motor. SPWM providing unbalanced two-phase inverter outputs is used. The dynamic model and simulation under steady state and dynamic operations are given. The design of a simple control method is proposed. The simulation and experimental results have shown the capability of the proposed system. As a consequence a practically variable speed application of the unbalanced twophase induction motor is possible with the proposed system.

\section{Acknowledgment}

The authors wish to thank Dr. Chakrapong Charumit, Department of Electrical Power Engineering, Mahanakorn University of Technology, Bangkok, Thailand for his valuable suggestion.

(Manuscript received July 6, 2009,

revised Feb. 22, 2010) 


\section{References}

( 1 ) C.-M. Young, C.-C. Lui, and C.-H. Lui: "New inverter-driven design and control method for two-phase induction motor drives", IEE Proc. on Electric Power Applications, Vol.143, No.6, pp.458-466 (1996)

( 2 ) F. Blaabjerg, F. Lungeanu, K. Skaug, and M. Tonnes: "Evaluation of LowCost Topologies for Two Phase Induction Motor Drives, in Industrial Applications", IEEE Proc. PCC-2002 Conf., pp.2358-2365 (2002)

( 3 ) S. Sinthusonthichat and V. Kinnares: "A new modulation strategy for unbalanced two phase induction motor drives using a three-leg voltage source inverter", IEEJ Trans. Ind. Appl., Vol.125, No.6, pp.482-491 (2005)

( 4 ) E.R. Benedict and T.A. Lipo: "Improved PWM Modulation for a PermanentSplit Capacitor Motor", in Proc. IEEE, IAS, Conf., Vol.3, pp.2004-2010 (2000)

( 5 ) J. Yao, J. Krase, and T.A. Lipo: "Design consideration for motor-controller integration of a single phase induction motor packaged drive", IEMDC 03 Conf., Vol.3, pp.2004-2010 (2003)

( 6 ) M.B. de Rossiter Correa, C.B. Jacobina, A.M.N. Lima, and E.R.C. da Silva: "A three-leg voltage source inverter for two-phase ac motor drive Systems", IEEE Trans. on Power Electronics, Vol.17, No.4, pp.517-523 (2002)

( 7 ) M.A. Jabbar, A.M. Khambadkone, and Z. Yanfeng: "Space-vector modulation in a two phase induction motor drive for constant-power operation", IEEE Trans. Ind. Electr., Vol.51, No.5, pp.1081-1088 (2004)

( 8 ) D.C. Martins, L.C. Tomaselli, T.B. Lazzarin, and I. Barbi: "Drive for a Symmetrical Two-phase Induction Machine Using Vector Modulation", IEEJ Trans. on Industrial Application, Vol.126, No.7, pp.853-840 (2006)

( 9 ) D.-H. Jang: "PWM methods for two- phase inverters", IEEE Ind. Appl. Mag., Vol.13, No.2, pp.50-61 (2007)

(10) S. Sinthusonthichat and V. Kinnares: "Performance evaluation of variable speed two phase induction motor", IEEE Proc. Power Con 2002 Conf., Vol.4, pp.2565-2568 (2002)

(11) D.-H. Jang and D.-Y. Yoon: "Space Vector PWM Technique For Two-Phase Inverter-Fed Single-Phase Induction Motors", IEEE Ind. Appl. Conf., ThirtyFourth IAS Annual Meeting, Conf. Rec., Vol.1, No.3-7, pp.47-53 (1999)

(12) D.G. Holmes and A. Kotsopoulos: "Variable Speed control of Single and Two Phase Induction Motors Using a Three Phase Voltage Source Inverter", Proc., IAS93, pp.613-620 (1991)

(13) E.R. Collins, Jr., H.B. Puttgen, and W.E. Sayle, II: "Single-Phase Induction Motor Adjustable Speed Drive: Direct phase Angle Control of The Auxiliary Winding Supply", Proc. of IEEE IAS88, Vol.1, pp.246-252 (1988)

(14) E.R. Collins, Jr. and R.E. Ashley: "Operating Characteristics of single-phase capacitor motor driven from variable frequency supplies", IEEE IAS-91, Conf. Vol.1, pp.52-57 (1991)

(15) D.G. Holmes and T.A. Lipo: "Pulse Width Modulation for Power Converters", Wiley Interscience, IEEE Press, pp.259-270 (2003)

(16) N.M. Abdel-Rahim and A.A. Shaltout: "Slip-Frequency Control of Single and Two Phase Induction Motors Operated as Two-Phase Motor", The $30^{\text {th }}$ Annual Conference of the IEEE Industrial Electronics Society, 2-6 November, Busan, Koren (2004)

(17) S.-M. Yang, F.-C. lin, and M.-C. Chen: "Control of a two-phase linear stepping motor with three-phase voltage source inverter", IEMDC 03 Conf., Vol.3, pp.1720-1725 (2003)

(18) N. Abdel-Rahim and A. Shaltout: "Operation of single-phase induction motor as two-phase motor", IECON'02, Vol.2, pp.967-972 (2000)

(19) B.K. Bose: "Modern Power Electronics and AC Drives", Prentice Hall PTR (2002)

(20) N. Mohan: "Advanced Electric Drives", Mnpere Minneapolis (2001)

(21) K. Ogata: "Modern Control Engineering", Prentice Hall, Inc. (2002)

(22) M.B. de Rossiter Correa, C.B. Jacobina, E.R.C. da Silva, and A.M.N. Lima: "Vector Control Strategies for Single-Phase Induction Motor Drive Systems", IEEE Trans. on Industrial Electronics, Vol.51, No.5, pp.1073-1080 (2004)
(23) Sh. Reicy and S. Vaez-Zadeh: "Vector Control of Single-Phase Machine with Maximum Torque Operation", IEEE ISIE05, Dubrovnik, Croatia, pp.923928 (2005)

(24) K.J. Lee, H.G. Kim, D.K. Lee, T.W. Chun, and E.C. Nho: "High Performance Drive of Single-Phase Induction Motor", in Proc., ISIE 2001, Vol.2, pp.983-988 (2001)

(25) V.S. Fating, S.V. Jadhav, R.T. Ugale, and B.N. Chaudhari: "Direct Torque Control of Symmetrical and Asymmetrical Single Phase Induction Motor", IEEE Power India Conf., pp.1-4 (2008)

(26) M.B.R. Correa, C.B. Jacobina, P.M. Santos, E.C. dos Santos, and A.M.N. Lima: "Sensorless Control Strategies for Single-Phase Induction Motor Drive System”, PESC '05. IEEE 36th, pp.707-713 (2005)

\section{Appendix}

app. Table 1. Asymmetrical two-phase induction motor parameters

\begin{tabular}{|c|c|c|c|}
\hline$R_{s d}$ & $8.97 \Omega$ & $R_{s q}$ & $48.80 \Omega$ \\
\hline$L_{s d}$ & $511.2 \mathrm{mH}$ & $L_{s q}$ & $1637.804 \mathrm{mH}$ \\
\hline$M_{s r d}$ & $466.171 \mathrm{mH}$ & $M_{s r q}$ & $1452.224 \mathrm{mH}$ \\
\hline$L_{r d}$ & $511.2 \mathrm{mH}$ & $L_{r q}$ & $1637.804 \mathrm{mH}$ \\
\hline$\alpha$ & 1.75 & $P$ & 2 \\
\hline$J$ & $0.01 \mathrm{kgm}^{2}$ & $B$ & $0 \mathrm{kgm}^{2} / \mathrm{s}$ \\
\hline
\end{tabular}

Wekin Piyarat (Non-member) received the B.Eng. (EE) degree from

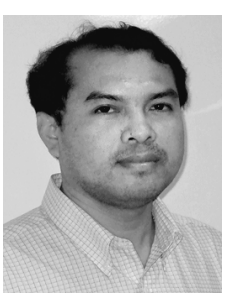
South-East Asia University, Bangkok, Thailand, and the M.Eng. (EE) degree from King Mongkut's Institute of Technology Ladkrabang, Thailand, in 1994 and 1998, respectively. He is currently working toward the D.Eng. degree in electrical engineering at King Mongkut's Institute of Technology Ladkrabang, Thailand. His research interests include power electronic, electric drives and control system application.

Vijit Kinnares (Non-member) received the B.Eng. and M. Eng. De-

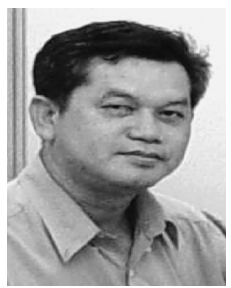
grees from King Mongkut's Institute of Technology Ladkrabang, Thailand. He received the Ph.D. degree from the University of Nottingham, U.K. in 1997. He has been an associate professor with King Mongkut's Institute of Technology Ladkrabang since 2003. His research interest includes energy conversion, power electronics and electric drives. 